\title{
The importance of left ventricular function for long-term outcome after primary percutaneous coronary intervention
} Pieter A van der Vleuten*1, Saman Rasoul ${ }^{2}$, Willem Huurnink ${ }^{3}$, Iwan CC van der Horst ${ }^{1}$, Riemer HJA Slart ${ }^{4}$, Stoffer Reiffers, Rudi A Dierckx ${ }^{4}$, René A Tio ${ }^{1}$, Jan Paul Ottervanger ${ }^{2}$, Menko-Jan De Boer ${ }^{2}$ and Felix Zijlstra1

Address: ${ }^{1}$ Thoraxcentre, Department of Cardiology, University Medical Centre Groningen, The Netherlands, ${ }^{2}$ Department of Cardiology, Isala klinieken, Zwolle, The Netherlands, ${ }^{3}$ Department of Nuclear Medicine, Isala klinieken, Zwolle, The Netherlands and ${ }^{4}$ Department of Nuclear Medicine and molecular imaging, University Medical Centre Groningen, The Netherlands

Email: Pieter A van der Vleuten* - p.a.van.der.vleuten@thorax.umcg.nl; Saman Rasoul - s.rasoul@isala.nl; Willem Huurnink - w.huurnink@isalaklinieken.nl; Iwan CC van der Horst - i.c.van.der.horst@thorax.umcg.nl; Riemer HJA Slart - r.h.j.a.slart@nucl.umcg.nl; Stoffer Reiffers - s.reiffers@isala.nl; Rudi A Dierckx - r.a.dierckx@nucl.umcg.nl; René A Tio - r.a.tio@thorax.umcg.nl; Jan Paul Ottervanger - j.p.ottervanger@isala.nl; Menko-Jan De Boer - m.j.de.boer@isala.nl; Felix Zijlstra - f.zijlstra@thorax.umcg.nl

* Corresponding author

Published: 23 February 2008

BMC Cardiovascular Disorders 2008, 8:4 doi:10.1186/147I-2261-8-4

This article is available from: http://www.biomedcentral.com/|47|-226I/8/4

(C) 2008 van der Vleuten et al; licensee BioMed Central Ltd.

This is an Open Access article distributed under the terms of the Creative Commons Attribution License (http://creativecommons.org/licenses/by/2.0), which permits unrestricted use, distribution, and reproduction in any medium, provided the original work is properly cited.
Received: 20 July 2007

Accepted: 23 February 2008

\begin{abstract}
Background: In the present study we sought to determine the long-term prognostic value of left ventricular ejection fraction (LVEF), assessed by planar radionuclide ventriculography (PRV), after ST-elevation myocardial infarction (STEMI) treated with primary percutaneous coronary intervention (PPCl).
\end{abstract}

Methods: In total 925 patients underwent PRV for LVEF assessment after PPCI for myocardial infarction before discharge from the hospital. PRV was performed with a standard dose of $500 \mathrm{Mbq}$ of $99 \mathrm{mT}$ c-pertechnetate. Average follow-up time was 2.5 years.

Results: Mean ( \pm SD) age was $60 \pm 12$ years. Mean $( \pm$ SD) LVEF was $45.7 \pm 12.2 \%$. I year survival was $97.3 \%$ and 3 year survival was $94.2 \%$. Killip class, multi vessel-disease, previous cardiovascular events, peak creatin kinase and its MB fraction, age and LVEF proved to be univariate predictors of mortality. When entered in a forward conditional Cox regression model age and LVEF were independent predictors of I and 3 year mortality.

Conclusion: LVEF assessed by PRV is a powerful independent predictor of long term mortality after PPCI for STEMI.

\section{Background}

The management of patients with an acute ST-elevation myocardial infarction (STEMI) has fundamentally changed over the last twenty years. In the eighties thrombolytic agents were introduced and more recently primary percutaneous coronary intervention (PPCI) has been shown to be even more effective $[1,2]$. In patients surviving the first days after PPCI, risk stratification is of great clinical relevance for the further (medical) management. Among others, global left ventricular function has always 
been viewed as an important prognostic factor after acute myocardial infarction. Earlier trials in large cohorts of STEMI-patients, treated with either thrombolytic agents or supportive care (no reperfusion-therapy), have confirmed this prognostic value for a period of six months after myocardial infarction [3-7].

Planar radionuclide ventriculography (PRV) is a well established and widely used technique for the assessment of left ventricular function. The technique is simple, robust and easy to perform [8-10]. PRV assesses LVEF by measurement of photon-activity of the bloodpool in the left ventricle in both the end-diastolic and end-systolic phase of the cardiac cycle. The aim of the present study was to evaluate the long term prognostic value of LVEF, assessed by routine PRV, in a large cohort of patients treated with PPCI for STEMI.

\section{Methods}

As part of two consecutive multicentre randomized controlled trials consecutive patients treated with PPCI for STEMI in two large hospitals in the Netherlands were entered in a registry $[11,12]$. The registry was opened in April 1998 and was closed in December 2004. The inclusion criteria differed in inclusion of all Killip classes in GIPS 1 [11] versus only Killip 1 in GIPS 2 [12]. Baseline characteristics such as medical history, cardiovascular risk factors, heart rate and blood pressure, delay-times and procedural parameters were recorded. For the present study data from the registries of two large hospitals in The Netherlands were used. Average follow-up time was 2.5 years. No patients were lost to follow-up. The present study was conducted in accordance with the declaration of Helsinki and was approved by the institutional review boards of both cooperating hospitals.

PRV was performed in routine clinical practice before discharge from the hospital, between day 1 and day 11 after myocardial infarction. Four patients with atrial fibrillation were excluded. Measurements were performed using the multiple-gated equilibrium method with in vivo labelling of red blood cells with 99mTc pertechnetate, after pre-treatment with $1 \mathrm{mg}$. of stannous chloride. A $\gamma$-camera (General Electric, Milwaukee, WI, U.S.A.) was used. The camera head was positioned in the best septal LAO projection, typically with a caudal tilt of 5-10 degrees. R-wave triggering was performed in a $20 \%$ beat acceptance window with $2 / 3$ forward and $1 / 3$ backward framing per cardiac cycle, for 20 frames per R-R interval for a total of 6 minutes. LVEF was calculated using a Star View computer (General Electric, Wisconsin, USA) using the fully automatic PAGE program (version 2.3). The standard deviation of the difference between repeat measurements obtained by this technique is $1-2 \%$ [13].

\section{Statistical analyses}

Analyses were performed with the commercially available package SPSS version 12.0.1 (SPSS inc, Chicago, IL, USA). Continuous data of LVEF values were expressed as mean \pm standard deviation (SD). Mortality rates were calculated according to the product-limit method. Further estimation of risk was performed using Cox proportional hazards models. Variables considered as potential predictors for multivariable modelling were selected by univariate analyses and were subsequently selected by stepwise forward selection, with entry and retention in the model set at a significance level of .05.

\section{Results}

PRV was not performed in 14 patients because they were too hemodynamically unstable. Furthermore 10 patients died before PRV could be performed. In total 925 patients underwent routine PRV. Clinical and angiographic characteristics are shown in Table 1. All patients underwent PPCI of the infarct related artery, which was successful in $87.2 \%$ (defined as TIMI 3 flow in combination with a myocardial blush grade $\geq 2$ ). PRV was performed at a median of 2 days after PPCI (range 1 day - 11 days). Mean LVEF was $45.7 \pm 12.2 \%$ (interquartile-range: $37.0 \%$ $54.0 \%)$.

Follow-up was obtained for all 925 patients. All-cause mortality was $0.2 \%, 0.9 \%, 2.7 \%$ and $5.8 \%$ at 3 days, 30 days, 1 year and 3 years respectively. Three day mortality in the entire registry was $2.3 \%$. Kaplan Meier curves for all-cause mortality in the 925 patients who underwent PRV before discharge are shown in Figure 1 . The unadjusted mortality rate increased exponentially with decreasing LVEF (Figure 2).

By univariate Cox proportional hazards analysis several baseline clinical characteristics and infarct related parameters were shown to be significant predictors of death. Significant predictors of both 1 year and 3 year mortality were age, history of MI, history of PCI, peak CK, peak CKMB-fraction and LVEF. Killip class, multivessel disease and history of CABG were only significant univariate predictors of 3 year mortality. Details are shown in Table 2. Sex, history of stroke, diabetes, hypertension, hyperlipidemia, smoking habit, positive family history, infarctduration, infarct location, TIMI flow after PPCI, myocardial blush grade, use of G2b3a inhibitors, use of intra-aortic balloon pump or mechanical ventilation were not significant predictors of mortality. When a forward conditional Cox proportional hazard model of only the factors age and LVEF was implemented, none of the other variables provided incremental prognostic value (Table 3 ). 
Table I: Baseline clinical and angiographic characteristics

\begin{tabular}{|c|c|}
\hline Age, yrs (mean \pm SD) & $59.8 \pm 12.0$ \\
\hline Male sex & 77.8 \\
\hline Body mass index, $\mathrm{kg} / \mathrm{m} 2($ mean $\pm \mathrm{SD})$ & $26.7 \pm 3.8$ \\
\hline History of MI & 9.9 \\
\hline History of $\mathrm{PCl}$ & 5.1 \\
\hline History of CABG & 2.8 \\
\hline History of stroke & 2.8 \\
\hline Diabetes mellitus & 9.7 \\
\hline Hypertension & 28.5 \\
\hline Hyperlipidemia & 22.1 \\
\hline Current smoker & 50.7 \\
\hline Positive family history & 42.3 \\
\hline Ischemia duration, min $(\text { mean } \pm S D)^{*}$ & $205 \pm 212$ \\
\hline Killip class I & 95.9 \\
\hline Killip class 2 & 2.4 \\
\hline Killip class 3 & 1.3 \\
\hline Killip class 4 & 0.4 \\
\hline Anterior $\mathrm{MI}$ & 48.6 \\
\hline Multivessel disease & 51.4 \\
\hline TIMI 3 flow after PCI & 96.9 \\
\hline Successful reperfusion $\ddagger$ & 87.2 \\
\hline Intra-aortic balloon pump & 5.0 \\
\hline Mechanical ventilation & 0.5 \\
\hline Stent & 57.6 \\
\hline Glycoprotein Ilb/Illa receptor blocker & 21.2 \\
\hline $\operatorname{Max} C K, U / I($ mean $\pm S D)$ & $2450 \pm 2159$ \\
\hline Max CK-MB, U/l (mean \pm SD) & $248 \pm 198$ \\
\hline
\end{tabular}

Data are displayed as percentage, unless otherwise indicated. *Ischemia duration denotes time between onset of symptoms and until PCI; łsuccessful reperfusion denotes TIMI 3 flow and myocardial blush grade 2 or 3 ;

$C A B G=$ coronary artery bypass grafting

$\mathrm{CK}=$ creatin kinase

CK-MB = creatin kinase myoglobin binding

$\mathrm{MI}=$ myocardial infarction

$\mathrm{PCl}=$ percutaneous coronary intervention

$\mathrm{SD}=$ standard deviation

$\mathrm{TIMI}=$ thrombolysis in myocardial infarction

\section{Discussion}

The present study shows that LVEF assessed shortly after PPCI for STEMI, is a powerful predictor of long term survival. Earlier studies, most designed to establish the value of various pharmacologic interventions after myocardial infarction, have shown the prognostic value of global left ventricular function, measured as LVEF, in terms of mortality and re-admission rates for heart failure [14-17]. However, the follow-up duration and patient selection differed from the present study.
Table 2: Predictors of I and 3 year mortality by univariate Cox proportional hazard analysis.

\begin{tabular}{|c|c|c|}
\hline \multicolumn{3}{|l|}{ I year mortality } \\
\hline Characteristics & Hazard ratio $(95 \% \mathrm{Cl})$ & $p$ \\
\hline Age, per 10 years increase & $2.00(1.35-2.97)$ & 0.001 \\
\hline Previous MI & $2.91(1.16-7.28)$ & 0.023 \\
\hline Previous $\mathrm{PCl}$ & $9.58(4.13-22.21)$ & $<0.001$ \\
\hline Max CK, per $500 \mathrm{U} / \mathrm{l}$ increase & $1.01(1.00-1.02)$ & 0.050 \\
\hline Max CK-MB, per $50 \mathrm{U} / \mathrm{l}$ increase & $1.09(1.01-1.18)$ & 0.039 \\
\hline LVEF, per $5 \%$ decrease & $1.47(1.25-1.73)$ & $<0.001$ \\
\hline \multicolumn{3}{|l|}{3 year mortality } \\
\hline Characteristics & Hazard ratio $(95 \% \mathrm{Cl})$ & $p$ \\
\hline Age, per 10 years increase & $1.63(1.25-2.14)$ & $<0.001$ \\
\hline Previous MI & $2.19(1.06-4.52)$ & 0.035 \\
\hline Previous $\mathrm{PCl}$ & $5.16(2.50-10.7)$ & $<0.001$ \\
\hline Previous CABG & $3.27(1.17-9.10)$ & 0.024 \\
\hline Multi-vessel disease & $1.50(1.06-2.11)$ & 0.021 \\
\hline Killip class, per class increase & $1.73(1.08-2.75)$ & 0.022 \\
\hline Max CK, per $500 \mathrm{U} / \mathrm{l}$ increase & $1.01(1.00-1.02)$ & 0.040 \\
\hline Max CK-MB, per $50 \mathrm{U} / \mathrm{l}$ increase & $1.07(1.01-1.14)$ & 0.020 \\
\hline LVEF, per $5 \%$ decrease & $1.29(1.15-1.46)$ & $<0.001$ \\
\hline \multicolumn{3}{|c|}{$\begin{array}{l}\text { CABG = coronary artery bypass grafting } \\
C K=\text { creatin kinase } \\
\text { CK-MB = creatin kinase myoglobin binding } \\
\text { LVEF = left ventricular ejection fraction } \\
\text { MI = myocardial infarction } \\
\text { PCI = percutaneous coronary intervention }\end{array}$} \\
\hline
\end{tabular}

The event-rate was relatively low for a post-infarction cohort, with a 3 year mortality of only $5.8 \%$. The fact that this study looks at data from patients who underwent PRV on average 2 days after PPCI in the routine of daily clinical practice, in most cases just before discharge or transfer to another hospital, has systematically excluded patients who were too hemodynamically unstable to undergo PRV. For all analyses total mortality was used. It can be hypothesized that the relationship between LVEF and cause-specific mortality would be even stronger. The fact that the traditional risk-factors for coronary artery disease (sex, hypertension, diabetes, hyperlipidemia, smoking and family history) were not significant predictors of mortality may be explained by the fact that these risk-factors for the most part contributed to the occurrence of the index-MI itself and have only limited effect on the prognosis after the index-MI. In addition, a number of these risk-factors (hypertension, hyperlipidemia and smoking) is usually treated more aggressively after the index-MI. The fact that some infarct-treatment parameters, such as use of mechanical ventilation and use of IABP, were not significant predictors of mortality is most likely explained by the relatively low numbers in this cohort with a relatively low event-rate.

Noteworthy is the relatively small difference in prognosis between the patient category with LVEF between $35 \%$ and 


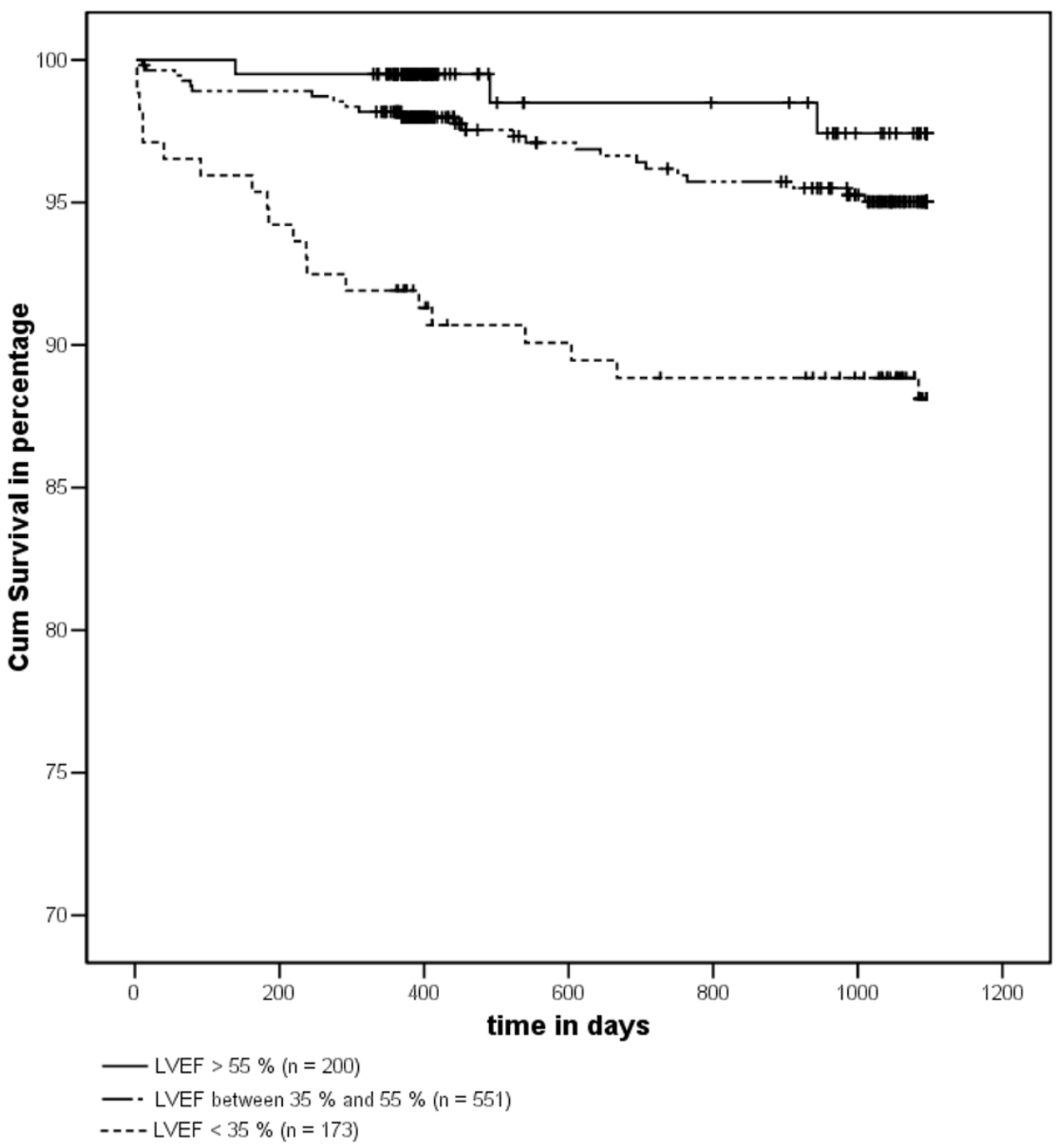

\section{Figure I}

Kaplan-Meier curve of 925 patients who underwent planar radionuclide ventriculography after primary percutaneous coronary intervention for ST-elevation myocardial infarction. LVEF = Left Ventricular Ejection Fraction.

$55 \%$ and the patient category with LVEF above $55 \%$, which is generally viewed as the lower limit of normal. In contrast, there was a large difference in survival between the patient category with LVEF between $35 \%$ and $55 \%$ and the patient category with LVEF below 35, which is the current cut-off point for implantable cardioverter defibrillator implementation (Figure 1).

The data in the present study suggest that markers of infarct size, such as maximum creatin kinase myoglobin binding level, Killip class and previous myocardial damage from earlier events add up to a risk burden which is related to global left ventricular function. LVEF can there- fore be viewed as a representative of the final common pathway of left ventricular damage when predicting longterm prognosis after PPCI. The fact that this LVEF-assessment can be performed just a few days after the index myocardial infarction facilitates simple and fast risk stratification after PPCI.

Besides PRV, LVEF can be measured by a number of techniques, which all have their own specific advantages and limitations. For instance echocardiography can be performed easily and at low cost. However, the diagnostic accuracy is limited [18]. Nuclear techniques such as positron emission tomography and single photon emission 


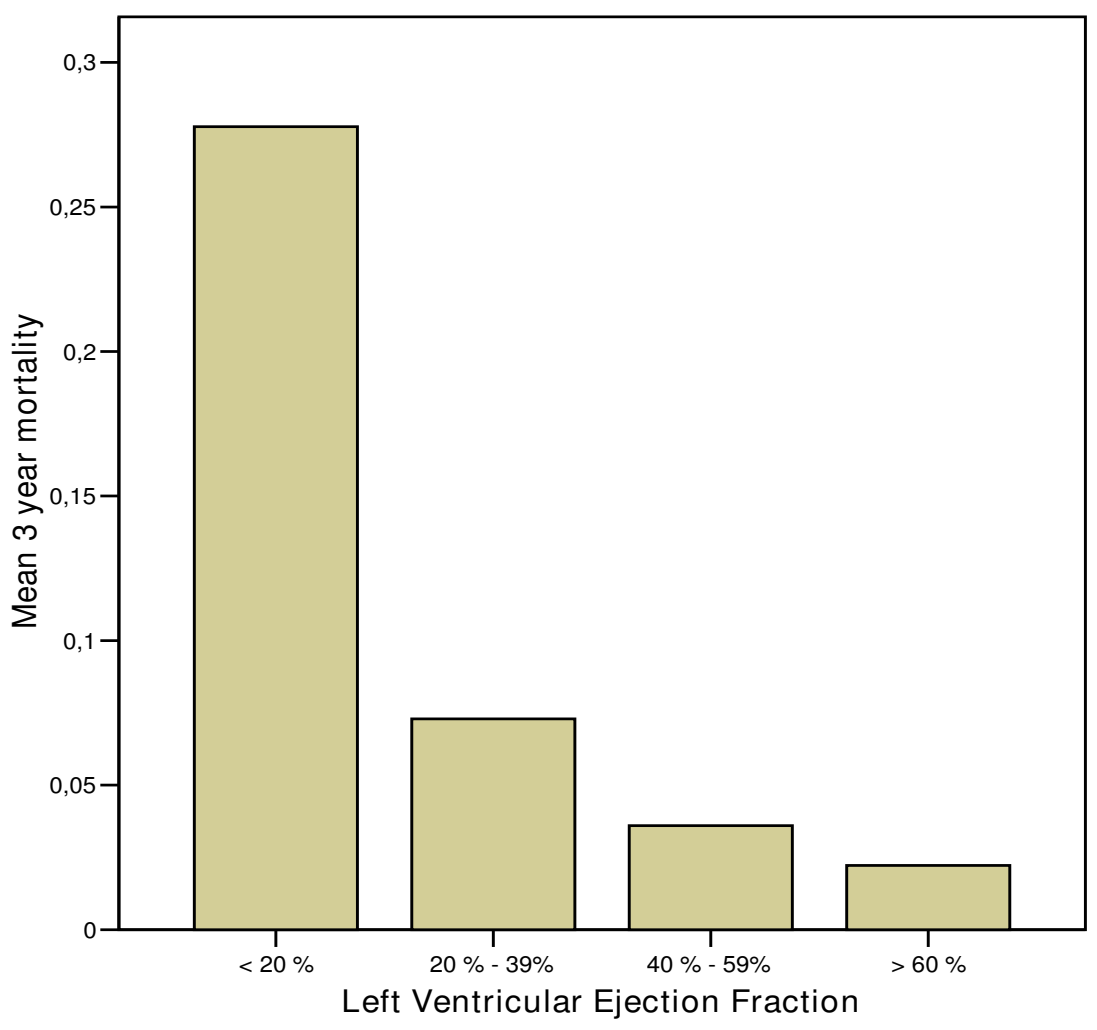

Figure 2

Adjusted 3 year mortality rate for patients who underwent planar radionuclide ventriculography after primary percutaneous coronary intervention for ST-elevation myocardial infarction, grouped by left ventricular ejection fraction.

computed tomography have better diagnostic accuracy, but are more labour intensive and are not available in every hospital. Recently, multi detector row computed tomography has been propagated as very fast and accurate technique for LVEF assessment [19]. However, besides ionising radiation, this technique also requires the use of intravenous nephrotoxic contrast agents. LVEF can even be assessed directly after PPCI by contrast ventriculography. Besides the obvious advantage of almost instant
LVEF-assessment, the main drawbacks from this approach are the relatively high volume of nephrotoxic contrast, the limited accuracy and the fact that LVEF can be severely underestimated by myocardial stunning shortly after STEMI. Magnetic resonance imaging is regarded by many to be the gold standard for LVEF measurement [20]. Unfortunately, this technique is limited to patients without intra-corporal devices such as pacemakers and is not generally available for routine clinical patients.

Table 3: Predictors of I and 3 years mortality by forward conditional Cox proportional hazard analysis.

\begin{tabular}{|c|c|c|c|c|}
\hline \multicolumn{5}{|l|}{ I year mortality } \\
\hline Characteristics & Hazard ratio & $95 \% \mathrm{Cl}$ & Wald $\chi^{2}$ & $p$ \\
\hline Age, per 10 years & 2.01 & $1.33-3.03$ & 11.1 & 0.001 \\
\hline LVEF, per $5 \%$ decreasing & 1.44 & $1.23-1.69$ & 20.4 & $<0.001$ \\
\hline \multicolumn{5}{|l|}{3 year mortality } \\
\hline Characteristics & Hazard ratio & $95 \% \mathrm{Cl}$ & Wald $\chi^{2}$ & $p$ \\
\hline Age, per 10 years & 1.64 & $1.25-2.15$ & 12.6 & $<0.001$ \\
\hline LVEF, per $5 \%$ decreasing & 1.28 & $\mathrm{I} .14-1.44$ & 17.6 & $<0.001$ \\
\hline
\end{tabular}

LVEF = left ventricular ejection fraction 


\section{Conclusion}

In conclusion, LVEF assessed by PRV before discharge from the hospital is a powerful independent predictor of long term prognosis after PPCI for STEMI.

\section{Abbreviations}

$\mathrm{CABG}=$ Coronary artery bypass grafting, $\mathrm{CK}=$ Creatin kinase, $\mathrm{CK}-\mathrm{MB}=$ Creatin kinase myocardial band, $\mathrm{LVEF}=$ Left ventricular ejection fraction, $\mathrm{PCI}=$ Percutaneous coronary intervention, PPCI = Primary percutaneous coronary intervention, PRV = Planar radionuclide ventriculography, SD = Standard deviation, STEMI = STelevation myocardial infarction, TIMI = Thrombolysis in myocardial infarction (study group).

\section{Competing interests}

The author(s) declare that they have no competing interests.

\section{Authors' contributions}

PVV contributed in data-collection, data-analysis and drafting the manuscript.

SR contributed in data-collection, data-analysis and drafting the manuscript.

WH contributed in PRV acquisition in Zwolle and drafting the manuscript.

ICH contributed in designing the study, data-analysis and drafting the manuscript.

RHS contributed in PRV acquisition in Groningen and drafting the manuscript.

SR contributed in designing the study, data-analysis and drafting the manuscript.

RAD contributed in data-analysis and drafting the manuscript.

RAT contributed in study-design, data-analysis and drafting the manuscript.

JPO contributed in study-design and drafting the manuscript.

MJB contributed in study-design and drafting the manuscript.

FZ contributed in study-design, data-analysis and drafting the manuscript.

All authors have read and approved the final version of the manuscript.

\section{References}

I. Zijlstra F, de Boer MJ, Hoorntje JC, Reiffers S, Reiber JH, Suryapranata $\mathrm{H}$ : A comparison of immediate coronary angioplasty with intravenous streptokinase in acute myocardial infarction. $N$ Engl J Med 1993, 328:680-684.

2. Keeley EC, Boura JA, Grines CL: Primary angioplasty versus intravenous thrombolytic therapy for acute myocardial infarction: a quantitative review of $\mathbf{2 3}$ randomised trials. Lancet 2003, 36 I: I 3-20.

3. St John SM, Pfeffer MA, Moye L, Plappert T, Rouleau JL, Lamas G, Rouleau J, Parker JO, Arnold MO, Sussex B, Braunwald E: Cardiovascular death and left ventricular remodeling two years after myocardial infarction: baseline predictors and impact of long-term use of captopril: information from the Survival and Ventricular Enlargement (SAVE) trial. Circulation 1997, 96:3294-3299.

4. Nicolosi GL, Latini R, Marino P, Maggioni AP, Barlera S, Franzosi MG, Geraci E, Santoro L, Tavazzi L, Tognoni G, Vecchio C, Volpi A: The prognostic value of predischarge quantitative two-dimensional echocardiographic measurements and the effects of early lisinopril treatment on left ventricular structure and function after acute myocardial infarction in the GISSI-3 Trial. Gruppo Italiano per lo Studio della Sopravvivenza nell'Infarto Miocardico. Eur Heart J 1996, I 7: I 646- I656.

5. Volpi A, De VC, Franzosi MG, Geraci E, Maggioni AP, Mauri F, Negri E, Santoro E, Tavazzi L, Tognoni G: Determinants of 6-month mortality in survivors of myocardial infarction after thrombolysis. Results of the GISSI-2 data base. The Ad hoc Working Group of the Gruppo Italiano per lo Studio della Sopravvivenza nell'Infarto Miocardico (GISSI)-2 Data Base. Circulation 1993, 88:416-429.

6. Pfeffer MA, Braunwald E, Moye LA, Basta L, Brown EJ Jr., Cuddy TE, Davis BR, Geltman EM, Goldman S, Flaker GC, .: Effect of captopril on mortality and morbidity in patients with left ventricular dysfunction after myocardial infarction. Results of the survival and ventricular enlargement trial. The SAVE Investigators. N Engl J Med 1992, 327:669-677.

7. Jensen-Urstad M, Samad BA, Jensen-Urstad K, Hulting J, Ruiz H, Bouvier $\mathrm{F}$, Hojer J: Risk assessment in patients with acute myocardial infarction treated with thrombolytic therapy. J Intern Med 200I, 249:527-537.

8. Abrams DS, Starling MR, Crawford MH, O'Rourke RA: Value of noninvasive techniques for predicting early complications in patients with clinical class II acute myocardial infarction. J Am Coll Cardiol 1983, 2:818-825.

9. Madanay LD, Cerqueira MD, Jacobson AF, Matsuoka D, Matsuda M, Stratton JR: Radionuclide ventriculographic quantitation of left ventricular dimensions. Comparison to echocardiography. Clin Nucl Med 1991, 16:588-592.

10. Rerych SK, Scholz PM, Newman GE, Sabiston DC Jr., Jones RH: Cardiac function at rest and during exercise in normals and in patients with coronary heart disease: evaluation by radionuclide angiocardiography. Ann Surg 1978, I 87:449-464.

II. van der Horst IC, Zijlstra F, van't Hof AW, Doggen CJ, de Boer MJ, Suryapranata H, Hoorntje JC, Dambrink JH, Gans RO, Bilo HJ: Glucose-insulin-potassium infusion inpatients treated with primary angioplasty for acute myocardial infarction: the glucose-insulin-potassium study: a randomized trial. J Am Coll Cardiol 2003, 42:784-79l.

12. Timmer JR, Svilaas T, Ottervanger JP, Henriques JP, Dambrink JH, van den Broek SA, van der Horst IC, Zijlstra F: Glucose-insulin-potassium infusion in patients with acute myocardial infarction without signs of heart failure: the Glucose-Insulin-Potassium Study (GIPS)-II. J Am Coll Cardiol 2006, 47:I730-I73I.

13. De Bondt P, De Winter O, Vandenberghe S, Vandevijver F, Segers $P$, Bleukx A, Ham H, Verdonck P, Dierckx RA: Accuracy of commercially available processing algorithms for planar radionuclide ventriculography using data for a dynamic left ventricular phantom. Nucl Med Commun 2004, 25: I 197-I202.

14. Mehta RH, O'neill WW, Harjai KJ, Cox DA, Brodie BR, Boura J, Grines L, Stone GW, Grines CL: Prediction of one-year mortality among 30-day survivors after primary percutaneous coronary interventions. Am J Cardiol 2006, 97:817-822.

15. Ottervanger JP, Ramdat Misier AR, Dambrink JH, de Boer MJ, Hoorntje JC, Gosselink AT, Suryapranata H, Reiffers S, van 't Hof AW: Mortality in patients with left ventricular ejection fraction </ 
$=\mathbf{3 0} \%$ after primary percutaneous coronary intervention for ST-elevation myocardial infarction. Am J Cardiol 2007, 100:793-797.

16. Ndrepepa G, Mehilli J, Martinoff S, Schwaiger M, Schomig A, Kastrati $A$ : Evolution of left ventricular ejection fraction and its relationship to infarct size after acute myocardial infarction. J Am Coll Cardiol 2007, 50: I49-I 56.

17. Dutcher JR, Kahn J, Grines C, Franklin B: Comparison of left ventricular ejection fraction and exercise capacity as predictors of two- and five-year mortality following acute myocardial infarction. Am J Cardiol 2007, 99:436-44I.

18. Chuang ML, Danias PG, Riley MF, Hibberd MG, Manning WJ, Douglas PS: Effect of increased body mass index on accuracy of twodimensional echocardiography for measurement of left ventricular volume, ejection fraction, and mass. Am J Cardiol 200 I, 87:37I-4, AI0.

19. Yamamuro M, Tadamura E, Kubo S, Toyoda H, Nishina T, Ohba M, Hosokawa R, Kimura T, Tamaki N, Komeda M, Kita T, Konishi J: Cardiac functional analysis with multi-detector row $C T$ and segmental reconstruction algorithm: comparison with echocardiography, SPECT, and MR imaging. Radiology 2005, 234:38I-390.

20. Pattynama PM, De RA, Van der Wall EE, Van Voorthuisen AE: Evaluation of cardiac function with magnetic resonance imaging. Am Heart J 1994, I 28:595-607.

\section{Pre-publication history}

The pre-publication history for this paper can be accessed here:

http://www.biomedcentral.com/1471-2261/8/4/prepub

Publish with Bio Med Central and every scientist can read your work free of charge

"BioMed Central will be the most significant development for disseminating the results of biomedical research in our lifetime. "

Sir Paul Nurse, Cancer Research UK

Your research papers will be:

- available free of charge to the entire biomedical community

- peer reviewed and published immediately upon acceptance

- cited in PubMed and archived on PubMed Central

- yours - you keep the copyright

Submit your manuscript here:

http://www.biomedcentral.com/info/publishing_adv.asp 